\title{
THE INTERCULTURAL ASPECT OF DISTANCE EDUCATION IN GREECE: A CASE STUDY OF EXPLORING EDUCATIONAL LEADERSHIP'S REPRESENTATIONS DURING THE COVID-19 PANDEMIC
}

\author{
Nektaria Sakkoula* \\ Hellenic Open University, Greece
}

\begin{abstract}
Intercultural education in Greece has recently been brought to the foreground, due to the worldwide migrant/refugee crisis. However, the COVID-19 pandemic outburst in 2020 forced distance education and, hence, technology utilization upon all stakeholders. In this regard, by adopting a qualitative approach and by exploring educational leaders' representations, this paper aims to investigate whether intercultural and distance education principles can be combined in order for students with a different cultural background to continue attending their lessons, as most native students do. The findings of this study demonstrate that intercultural principles are hard or in some cases impossible to be applied in distance learning and consequently, refugee/migrant students end up falling behind or being entirely excluded from the educational process.
\end{abstract}

Keywords: intercultural education, distance education, ICT utilization, school principals

Intercultural education has been a subject of heated debate since it first appeared in Greece in the 1970s, when a great number of immigrant Greeks returned to the country to resettle (Trouki, 2012). The repatriation of these populations led to the creation of intercultural schools, where all students are immigrants and/or refugees, as well as to the creation of host classes within typical schools, where immigrant and/or refugee students are divided into two groups, according to their knowledge of Greek language and with a view to joining typical classes when they have reached the appropriate linguistic level (Palaiologou \& Dimitriadou, 2013; Trouki, 2012; Paleologou, 2004).

Although these school settings were firstly designed to support only Greek diaspora students, the recent migration crisis has imposed their reformation in order for them to be able to accommodate all students' needs, regardless of their cultural background and origins (Pandolfini, 2016; Palaiologou \& Dimitriadou, 2013; Paleologou, 2004). In this context and towards a more intercultural school, recent research has shown that intercultural principles cannot fully and successfully be applied, without implementing Information and Communication Technologies (ICT) (Pandolfini, 2016; Nikolopoulou \& Gialamas, 2015, 2016). ICT use during lessons enhances intercultural education, by promoting interactions, creating a friendly class environment, as well as offering educational opportunities to all students, while allowing them to maintain their cultural identity (Sakkoula \& Kitsiou, 2021; Pandolfini, 2016).

However, the Greek educational system seems to be unwilling and unprepared to both adequately apply intercultural principles and utilize ICT for intercultural purposes, despite the numerous educational benefits they offer (Nikolopoulou \& Gialamas, 2015, 2016). On top of that, the outburst 
of the COVID-19 pandemic changed the educational reality, as distance education, and - therefore ICT utilization became obligatory, not only during the lockdown, but in any occasions where face-toface teaching is impossible or dangerous for students.

Hence, in this regard, by exploring the educational leadership's representations, this paper aims to examine whether and how intercultural principles are applied in the context of distance education, during the COVID-19 pandemic with an emphasis on ICT use. The rest of the paper is organized as follows: Section 2 presents related work, regarding the contribution of ICT to connecting intercultural and distance education, as well as the school principal's role in implementing both educational forms with the use of ICT. Section 3 refers to research methodology that was adopted, while Section 4 presents the most important research findings. Finally, in Section 5, these findings are further discussed and future research proposals are made.

\section{Related Work}

\section{ICT: Connecting intercultural with distance education}

According to Albugami and Ahmed (2015) and Uluyol and Şahin (2014), ICT implementation is the future of education. ICT are valuable tools in the hands of educators worldwide, as they transform, facilitate and differentiate the learning process, making it more appealing and accessible to both teachers and students (Pandolfini, 2016). Additionally, they combine traditional with modern teaching methods, bridging the gap between theory and practice, as well as between past, present and future (Livingstone, 2011).

More specifically, ICT - when used for educational purposes - promote empathy and acceptance, as they can bring different civilizations together and help students to further interact and, hence, embrace difference (Ribeiro, 2016). Furthermore, ICT utilization is in accordance with student - centered learning and the principles of constructivism, creating up-to-date curricula, which apply for every student population (Kim, 2018). Actually, the impact of ICT extends from schools to society, as the use of technology helps students develop their autonomy and become competitive citizens in the new globalized and intercultural societies of the $21^{\text {st }}$ century (Albugami \& Ahmed, 2015; Powers \& Green, 2016).

When it comes to intercultural, as well as distance education, ICT function supportively, as well. Intercultural and distance education share a mutual philosophy and a common goal to include all learners in the educational process, regardless of their location or cultural background (Kim, 2018; Lionarakis et al., 2019). However, while in distance education ICT utilization, by eliminating the physical distance between educators and students, becomes essential and unavoidable, (Lionarakis et al., 2019; Tait, 2015), in intercultural education it is up to teachers and school principals whether they will exploit technology or not (Nikolopoulou \& Gialamas, 2015, 2016; Mingaine, 2013a, 2013b).

Taking the aforementioned findings into consideration, ICT utilization is in harmony with intercultural principles, as well as a vital part of distance education (Lionarakis et al., 2019; Sipilä, 2014; Tait, 2015). Therefore, technology can function as a connector between these two educational forms, promoting social justice and enhancing interculturalism in cases, where face-to-face education is impossible (Kim, 2018; Sipilä, 2014). As a result, distance and intercultural education - when 
combined - create a more inclusive school environment, which is accessible to all students, including refugees and migrants not being able to attend typical schools, due to their life conditions, their location and/or occasions, such as the current pandemic outburst (Kim, 2018; Sakkoula \& Kitsiou, 2021).

\section{"Digital" school leaders: From theory to practice}

In respect to ICT utilization for intercultural purposes, school principals' attitude seems to be of major importance (Mingaine, 2013a, 2013b). Despite the fact that teachers also contribute to using technology during lessons (Nikolopoulou \& Gialamas, 2015, 2016), the school principal is the keyfactor, as they shape school policy and influence both teachers and students towards the creation of an intercultural school (Mingaine, 2013a, 2013b). More specifically, they have multiple roles, as they function both as administrators and leaders and they are responsible for bureaucratic matters related to raising funds and finding equipment, as well as guiding/training their staff and maintaining a positive and inclusive school atmosphere (Mingaine, 2013a, 2013b; Ottestad, 2013). Consequently, ICT use depends on them and on the vision they have formed, regarding their school and the adopted practices (Mingaine 2013a, 2013b; Sakkoula \& Kitsiou, 2021).

Nevertheless, the leaders who apply intercultural principles share specific features. First of all, they have high self-confidence and problem-solving skills, so they can adapt to new conditions and support teachers, as well (Mingaine, 2013a, 2013b). Moreover, they believe in distributional leadership and urge teachers and students to take on initiatives, in order to reform school settings with a view to reforming society hereafter (Mingaine, 2013b; Ottestad, 2013). By recognizing the pedagogical value of ICT, school principals open their school to the community and to the world, establish beneficial cooperation and efficiently reach out to the (refugee/migrant) students' families, building strong communication bonds and including them in the educational process (Powers \& Green, 2016).

Although most school principals are willing to utilize ICT, they are reluctant, due to the numerous barriers they have to face (Mingaine, 2013a; Sakkoula \& Kitsiou, 2021). A very serious problem principals have to deal with is the lack of state support in terms of funding, as buying and maintaining the equipment is rather costly (Livingstone, 2011). Furthermore, they haven't been trained to use ICT for educational (and/or intercultural) purposes, and apart from that, it is essential that they convince the teachers, who don't want to use technology, because of their own perceptions and emotions, regarding ICT effectiveness (Sakkoula \& Kitsiou, 2021).

All things considered, when it comes to combining distance and intercultural education, where ICT utilization is obligatory, the already existing problems get worse and school principals end up carrying the burden of their own difficulties, as well as teachers' hesitations and the state's inadequacies (Sakkoula \& Kitsiou, 2021).

\section{Research Methodology}

\section{Research purpose \& research questions}

Although the relationship between distance education and ICT use (Lionarakis et al., 2019; Tait, 2015), as well as between intercultural education and ICT use (Pandolfini, 2016; Sipilä, 2014), has 
widely been investigated, there are no data regarding the intercultural features (if any) of distance education (Sakkoula \& Kitsiou, 2021). Furthermore, the fact that ICT aren't adequately utilized in Greek educational settings should be taken into consideration, as this can lead to distance education not being fully or appropriately applied and thus causing serious problems to the learning process and negatively affecting intercultural education as well (Nikolopoulou \& Gialamas, 2015, 2016; Sakkoula \& Kitsiou, 2021).

In this regard, this article aims to investigate whether and/or how intercultural principles are applied in distance education through ICT utilization, during the COVID-19 pandemic in Greece, by exploring school principals' representations. While previous research mostly focuses on ICT benefits and drawbacks in general education (Albugami \& Ahmed, 2015; Uluyol \& Şahin, 2016;), this paper offers an in-depth perspective and analysis of ICT utilization for intercultural purposes in distance education, during the unprecedented conditions of the worldwide pandemic. Therefore, three research questions were set to serve this purpose:

1. How do school principals perceive the educational value of ICT utilization for intercultural purposes in distance education?

2. How do school principals perceive the disadvantages occurring due to ICT utilization for intercultural purposes in distance education?

3. How do school principals perceive the barriers occurring during ICT utilization for intercultural purposes in distance education?

\section{Research sample \& techniques}

The current study was conducted during the first official lockdown in March and April, 2020, in Athens. A qualitative approach was applied, as the researcher's purpose was - by placing emphasis on educational leaders' representations - to deeply comprehend the conditions under which ICT are utilized in order for intercultural and distance education to be combined and for schools to accommodate all students' educational needs (Crow et al., 2017). Additionally, the qualitative approach is a flexible method, allowing further interactions between the researcher and the participants, as well as enhancing participants' self-reflections (Crow et al., 2017).

At the time of the study, 219 host classes within typical schools and 7 intercultural schools were active in Athens. As already mentioned, students attending these classes/schools are divided into 2 groups, according to their language level (Trouki, 2012). Therefore, the sample was determined, by using a purposive sampling technique and by choosing schools and/or classes where both groups had been formed before and co-existed during the quarantine (Creswell, 2011). The semi-structured interview was chosen as a research tool, as it allows the participants to analyze their views and enables the researcher to maintain control of the process (Tsiolis, 2014).

Hence, the sample consisted of 15 school principals, leading intercultural schools or typical schools with host classes ( 8 out of 15 lead primary schools with host classes, 4 out of 15 lead secondary schools with host classes and 3 out of 15 lead intercultural secondary schools). The school principals' age varied from 50 to 65 years old, while most participants were women (10 out of 15). As far as the school population is concerned, according to the participants, the percentage of refugee students 
ranged between $30 \%$ (in typical schools) and 100\% (in intercultural schools). Moreover, a common feature of these schools - with the exception of 2 primary schools - was the lack of facilities and the inability to provide teachers and (refugee/migrant) students with the technological equipment they needed in order to attend their online lessons.

To better investigate the principals' representations, an interview protocol was created, which places emphasis on ICT role in enhancing the intercultural character of distance education. The interview protocol was divided into 3 parts, in terms of the participants' views, regarding the educational benefits of using ICT for intercultural purposes in distance education, as well as the disadvantages and barriers that occur within ICT use in the same context. The trustworthiness (validity and reliability) of the study was established by the genuine communication between the researcher and the participants, the accurate record-keeping, the researcher's constant occupation with the topic, as well as the indepth data analysis, which allows the transferability of the results to other similar contexts (Lincoln \& Guba, 1985).

\section{Findings}

On the grounds that the researcher aimed to interpret the participants' representations, concerning interculturalism in distance education with the use of ICT, the interpretative approach of thematic data analysis was applied (Clarke et al., 2015; Tsiolis, 2014). Data were grouped and codified, according to the research purpose and research questions and, as a result, based on the mutual thematic centers among the interviewees' answers, five categories emerged: (a) enhancement of 21 st century learner skills through distance education and ICT use; (b) lack of equipment at home and/or school; (c) the significance of teachers' training; (d) the parental role; and (e) social isolation.

With regard to the first category, participants were asked about their opinions, regarding the effects of distance education and extensive ICT use on students. The outcomes show that they are divided. More specifically, 9 out of 15 principals believe that distance education - when appropriately applied - can help students develop 21 st century competencies, including interculturalism. As a primary school principal mentioned: "In order for distance education to succeed, students must know how to use ICT, which means handling the equipment, solve potential technological problems and co-exist and collaborate with different people in a virtual world. These skills will be rather useful to them, as adult citizens in modern societies", while another one added that "what seems to be considered a problem must be perceived as a chance. Most parents and students are technologically illiterate, not to mention teachers. This should change and now it's the time, as we are forced to adapt to this new way of learning." Additionally, a secondary school principal explained that "behind the screen they are all equal and they share the same experiences, pretty much as it should be in real world, too. The color or religion differences do not exist in online lessons." These findings are in accordance with Powers and Green (2016) and Albugami and Ahmed (2015), who support that ICT utilization in education prepares students for their life in intercultural, globalized societies of the 21 st century.

Nonetheless, 10 out of the 15 principals also pointed out that "in spite of these benefits, technology can't and mustn't substitute teachers and face-to-face learning altogether." Furthermore, "the most important factor in learning is the teacher and traditional methods shouldn't disappear. Technology is subsidiary, distance education is a temporal solution in an emergency situation and should remain that 
way." This evidence corroborates Powers and Green's (2016) findings, regarding the importance of combining ICT with traditional ways of teaching and not using it daily and exclusively.

As far as the second category is concerned, questions related to the existence of ICT facilities and equipment at school and/or at home, as well as funding and state support were posed to participants. It becomes obvious that the lack of technological equipment both at refugee students' homes and schools is of major importance. Thirteen out of 15 participants agreed that "the biggest problem is the fact that refugee and migrant students sometimes live in places where there is no access to technology at all. Not all refugee families have emails, laptops or mobile phones, either because they can't afford them or because their culture does not approve of them. So, it is hard for school to communicate with them and of course, these students can't attend online lessons." Moreover, a principal of an intercultural school stated that "the aftermath is obvious. Refugee students are already in a difficult position. Without being able to attend online lessons, not only do they fall behind at schoolwork, but the gap between them and native students, also, widens. During the lockdown, the effects of this situation are detrimental, if you ask me."

Schools, on the other hand, cannot accommodate refugee and migrant students' needs, regarding ICT provision, as 8 out of 15 interviewees mentioned that their schools don't have more than one or two computers, which are mostly used for administrative purposes. Two principals admitted that "some refugee students come to school, asking for help. They are keen to attend the lessons and they want us to provide them with laptops or tablets, but we barely have any," while another one states that "this is rather difficult for us. We would help them if we had the equipment or the funds, but you shouldn't forget that many of our teachers come to school for their online lessons. Schools don't have that much of equipment to serve all these needs and there is a huge lack of state care." Lastly, some of the participants conclude that "all these inequities preexisted the COVID-19 pandemic, but they have now become even more obvious. Taking this aspect into account, there is no interculturalism in distance education in Greece.” Therefore, as Sakkoula and Kitsiou (2021) and Mingaine (2013a, 2013b) mention, students - mostly due to financial inequities - are not offered the same opportunities in ICT access at home and at school, making it difficult for both distance and intercultural education to be applied.

Regarding the third category, principals were asked questions about teacher training and its importance in distance and intercultural education. Fourteen out of 15 principals admitted that training is a crucial factor in both educational forms, as well as maintaining the intercultural character of distance education, but they complained that there is no state or internal school care. As a principal argued, "the state doesn't give us any motivation to train, at all. The shortcoming is more than obvious. Neither principals nor teachers are trained in intercultural education or ICT. Some of the teachers are due to retire and don't know how to use a laptop. How will they be able to teach online effectively?" Nonetheless, only one participant claimed that he didn't feel that he should act differently, as "training is a personal initiative. I can't force my teachers to train, as I am not trained myself. The biggest needs have emerged due to the lockdown. Before that, training wasn't even a question. Should we train in something we haven't chosen or supported?" Hence, as Nikolopoulou and Gialamas $(2015,2016)$ have found, there is no state or internal school support regarding teachers' training and motivation. 
With respect to the fourth and fifth categories, questions related to the disadvantages of distance education and extensive ICT use in terms of unifying school community (including students, teachers, parents and society) were posed. As far as the fourth category is concerned, my findings demonstrate that parents' online behavior may have a negative impact on refugee and/or migrant students. Seven out of 15 participants stated that "an inevitable part of distance education is the use of social media, as a means of communication and collaboration. Many parents participate in online group chats and create a hostile atmosphere, which is imitated and transferred by students into the virtual class." As a result, "there is a huge increase in cyber-bullying, mostly affecting refugee and migrant students, as parents openly admit to not accepting them at school" and "during the quarantine, all these behaviors have worsened. What we have come to face is really unbelievable and parents are the ones to blame." These data corroborate Powers and Green's (2016) findings concerning the increase of cyber-bullying through ICT use and the existing literature regarding the parents' role.

As far as the fifth category is concerned, all participants, with no exceptions, placed great emphasis on the social isolation and the lack of communication, deriving from constant use of ICT combined with the lockdown restrictions. More specifically, two of the participants said that "children have already been addicted to technology and we try hard to make them leave their mobiles aside in face-to-face teaching. Now, they can't attend lessons without them, so this situation is just getting worse and worse" and "this is a bidirectional issue that absolutely affects refugee students. When they don't have the essential equipment, they can't be in touch with their classmates and friends and they lose their social life, if any. When they have the equipment needed to attend the lessons, they spend their whole day surfing the net on their own, without any limits." Finally, school principals agreed that "this social isolation makes migrants' and refugees' integration in school and society even more difficult." Hence, as Powers and Green (2016) have already concluded, overusing ICT for educational purposes can negatively affect refugee and immigrant students' social relationships and lead to their isolation.

\section{Conclusions}

In this paper, the intercultural character of distance education is being examined in the context of the SARS-Cov-2 pandemic, whose consequences have changed the educational reality in Greece and forced ICT utilization upon the learning process (Sakkoula \& Kitsiou, 2021). The research findings demonstrate that, despite the efforts schools make, maintaining an intercultural character in distance education is rather difficult.

In respect to the first research question, I tried to examine the way school principals perceive the educational value of ICT utilization within the combination of distance and intercultural education in Greece. Most participants state that distance education is a great way for students, as well as educators, to improve their skills, regarding interactions, communication, collaboration and technological literacy, in general. Additionally, they highlight the equity, deriving from ICT use during distance learning, as it eliminates cultural, color and religion differences, and hence, it promotes respect and acceptance, which are essential elements of intercultural education. These findings are consistent with those of Powers and Green (2016) and Albugami and Ahmed (2015), who support that ICT implementation enhances intercultural education, as well as 21st century learner skills. On the contrary, a few participants stand against the leading role of technology in education, claiming that distance education and continuous ICT use aren't beneficial. These principals, actually, 
maintain quite a passive attitude toward new pedagogical methods and changes, considering teachers responsible for all aspects of educational process. These data corroborate Sakkoula and Kitsiou's (2021) findings regarding the principals' passive perspective, whereas they are in contrast with Mingaine (2013a, 2013b) concerning the principal's being the key-person in ICT use for intercultural purposes.

In relation to the second research question, the disadvantages occurring due to extended ICT utilization in distance education mostly have to do with the social isolation of refugee and/or migrant students and the increase of cyber bullying. Most participants report that refugee and/or migrant students already face difficulties in their social life, because of their cultural differences, so, during the lockdown, they end up either losing contact with their classmates, especially when they don't have access to ICT in order to attend the lessons, or spending their whole day online, seeking for emotional comfort. In both cases, their social isolation leads to lack of intercultural communication and widens the distance between them and native students. These findings complete previous work, supporting that extended ICT use is not beneficial for (refugee/migrant) students, as it distracts them and negatively influences their school performance and social life in the host country (Powers \& Green, 2016).

Another important aspect, which is related to the second question, is the increase of cyber-bullying because of the parents' stance. My data demonstrate that there have been some online incidents on social media and other applications, caused by parents, which are imitated by children and destroy the friendly environment of online classes. Actually, principals state that parents who don't generally accept refugee and/or immigrant students exploit the lockdown and aim to exclude these children from classes by creating a hostile atmosphere. This evidence is in agreement with Powers and Green (2016) regarding the bullying that takes place online, while, it also is consistent with previous literature, as the parental factor in online lessons seems to be a new research field in terms of interculturalism.

With respect to the third question, participants agree that the two most important barriers occurring during online lessons are the lack of equipment and the lack of teachers' training. First of all, the lack of equipment reflects Greece's financial status and extends to both schools and refugee families. Most refugees either live in places with no ICT access or can't afford the essential equipment. On the other hand, schools aren't (adequately) equipped as well, and at the same time, they are obliged - when needed - to provide teachers with the essential gadgets for their online lessons. Hence, refugee and/or migrant students are excluded from the educational process and the cognitive and cultural distance between them and Greek students becomes wider. These findings complete those of Mingaine (2013a, 2013b), who claims that there is no actual state support and that schools have to find the funds and face the challenges without official help. Also, they add up to existing literature, since the inequities in terms of ICT access, are being studied in the light of the worldwide pandemic and distance learning.

Concerning the shortcoming in teachers' training, it comes hand in hand with the lack of state care and principals' mainly passive attitude. According to principals, teachers take on the responsibility of training themselves, by practicing alone or paying their participation to related programs, as there is no state and/or in-school programming. Consequently, having no motivation or support, they avoid training and especially, those who are close to retirement, leading themselves to rejecting ICT use and 
online lessons as well, due to their feelings of fear and insecurity. These findings are not completely in line with previous work, as it is claimed that school principal is the most determining factor in implementing ICT (Mingaine, 2013a, 2013b), whereas this isn't the case for Greece, where teachers seem to be on their own, during these efforts and cannot count on their superiors for support and guidance.

In this paper, I tried to investigate whether and how intercultural principles are applied in distance education with a focus on ICT utilization during the COVID-19 pandemic within Greek educational settings. There is no intention to generalize the results, as the qualitative approach was adopted and the sample was small and included only 15 principals, working in intercultural schools or schools with host classes. Despite its limitations, this study illustrates the way distance and intercultural education are combined in order for refugee and/or immigrant students to keep attending their lessons during the lockdown. Firstly, it highlights the educational benefits of distance education in terms of enhancing $21^{\text {st }}$ century learner skills, including interculturalism. Secondly, it presents new evidence regarding native parents' negative role in the relationships between native and refugee/immigrant students, during online lessons. Thirdly, it underlines the problems intercultural education faces when combined with distance education, concluding that there is no actual interculturalism in the latter and that intercultural education is mostly theoretical in Greece (Palaiologou \& Faas, 2012). While these problems apply for every student population, refugee and immigrant students are more easily affected and victimized, because of their cultural differences and background (Palaiologou \& Faas, 2012). On this basis, further research is proposed, applying a mixed methodological approach to a larger sample, including refugee and immigrant students.

\section{References}

Albugami, S., \& Ahmed, V. (2015). Success factors for ICT implementation in Saudi secondary schools: From the perspective of ICT directors, head teachers, teachers and students. International Journal of Education and Development using ICT, 11(1). Open Campus, The University of the West Indies, West Indies. Retrieved April 25, 2021 from https://www.learntechlib.org/p/151051/

Clarke, V., Braun, V., \& Hayfield, N. (2015). Thematic analysis. In J. Smith (Ed.), Qualitative psychology: A practical guide to research methods ( $3^{\text {rd }}$ ed.) (pp. $\left.222-248\right)$. Sage.

Creswell, J. W. (2011). Educational research: Planning, conducting, and evaluating quantitative and qualitative research. Allyn \& Bacon.

Crow, G., Day, C., \& Møller, J. (2017). Framing research on school principals' identities. International Journal of Leadership in Education, 20, 265-267. https://doi.org/10.1080/13603124.2015.1123299

Kim, S. (2018). ICT for children of immigrants: Indirect and total effects via self-efficacy on math performance. Journal of Educational Computing Research, 55(8), 1168 - 1200. https://doi.org/10.1177/0735633117699954

Lincoln, Y. S., \& Guba, E. (1985). Naturalistic inquiry. Sage.

Lionarakis, A., Papadimitriou, S., \& Ioakimidou, V. (2019). The Hellenic Open University: Innovations and challenges in Greek higher education. Open Education - The Journal for Open and Distance Education and Educational Technology, 15(1), 6 - 22. https://doi.org/10.12681/jode.20211

Livingstone, S. (2011). Critical reflections on the benefits of ICT in education. Oxford Review of Education, 38(1), 9 - 24. https://doi.org/10.1080/03054985.2011.577938 
Mingaine, L. (2013a). Challenges encountered by principals during implementation of ICT in public secondary schools, Kenya. Journal of Sociological Research, 4(2), 1 - 19. http://dx.doi.org/10.5296/jsr.v4i2.3552

Mingaine, L. (2013b). Leadership challenges in the implementation of ICT in public secondary schools, Kenya. Journal of Education and Learning, 2(1), 32 - 43. http://dx.doi.org/10.5539/jel.v2n1p32

Nikolopoulou, K., \& Gialamas V. (2016). Barriers to ICT use in high schools: Greek teachers' perceptions. Journal of Computers in Education, 3(1), $59-75$. https://doi.org/10.1007/s40692-015-0052-z

Nikolopoulou, K., \& Gialamas, V. (2015). Barriers to the integration of computers in early childhood settings: Teachers' perceptions. Education and Information Technologies, 20(2), 285 - 301. https://doi.org/10.1007/s10639-013-9281-9

Ottestad, G. (2013). School leadership for ICT and teachers' use of digital tools. Nordic Journal of Digital Literacy, 8, 107 - 125. Retrieved April 25, 2021 from https://www.idunn.no/dk/2013/0102

Palaiologou, N., \& Faas, D. (2012). How 'intercultural' is education in Greece? Insights from policy makers and educators. Compare: A Journal of Comparative and International Education, 42(4), 563-584. https://doi.org/10.1080/03057925.2012.658276

Palaiologou, N., \& Dimitriadou, C. (2013). Multicultural/intercultural education issues in pre-service teacher education courses: The case of Greece. Multicultural Education Review, 5(2), 49 - 84. https://doi.org/10.1080/2005615X.2013.11102902

Paleologou, N. (2004). Intercultural education and practice in Greece: Needs for bilingual intercultural programmes. Intercultural Education, 15(3), 317-329. https://doi.org/10.1080/1467598042000262608

Pandolfini, V. (2016). Exploring the impact of ICTs in education: Controversies and challenges. Italian Journal of Sociology of Education, 8(2), 28 - 53. http://dx.doi.org/10.14658/pupj-ijse2016-2-3

Powers, K., \& Green, M. (2016). Principals' perspectives on social media in schools. The Journal of Social Media in Society, 5(2), 134 - 168. Retrieved April 22, 2021 from https://www.thejsms.org/tsmri/index.php/TSMRI/article/view/174/82

Ribeiro, P. M. S. (2016). Developing intercultural awareness using digital storytelling. Language and

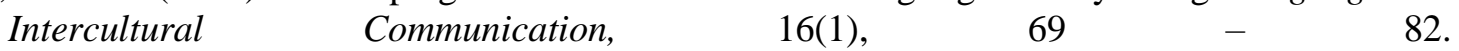
https://doi.org/10.1080/14708477.2015.1113752

Sakkoula, N., \& Kitsiou, A. (2021). The use of information and communication technologies in intercultural education in Greek primary and secondary educational settings: A case study of exploring school principals' and teachers' representations and practices. In V. Chiou, L. Geunis, O. Holz, N. O. Ertürk, \& F. Shelton (Eds.), Voices from the classroom: A celebration of learning (pp. 296 - 306). Waxmann.

Sipilä, K. (2014). Educational use of information and communications technology: teachers' perspective. Technology, Pedagogy \& Education, 23(2), $225-241$. https://doi.org/10.1080/1475939X.2013.813407

Tait, A. (2015). Student success in open, distance and e-learning. Paper presented at International Council for Open and Distance Education-ICDE, Oslo. Retrieved March 14, 2021 from https://eadtu.eu/news/20-general-news/257-student-success-in-open-distance-and-e-learning

Trouki, E. (2012). The challenge of cultural diversity in Greece: Reflections on "intercultural education schools" (IES) strategy for creating inclusive learning environments. Power and Education, 4(2), 219 - 229. https://doi.org/10.2304/power.2012.4.2.219

Tsiolis, G. (2014). Methods and techniques of analysis in qualitative social research. Kritiki. 
Sakkoula / The Intercultural Aspect of Distance Education in Greece. A Case Study of Exploring...

Uluyol, Ç., \& Şahin, S. (2016). Elementary school teachers' ICT use in the classroom and their motivators for using ICT. British Journal of Educational Technology, 47(1), 65 - 75. https://doi.org/10.1111/bjet.12220 